\title{
Temperature variability caused by internal tides in the coral reef ecosystem of Hanauma Bay, Hawai'i
}

Katharine A. Smitha, ${ }^{a}$, Greg Rocheleau ${ }^{a}, 1$, Mark A. Merrifielda, Sergio Jaramillob, Geno

Pawlak $^{c}$

a Department of Oceanography, University of Hawai'i at Mānoa, 1000 Pope Road, Honolulu, Hawaii 96822, USA

b Shell Global Solutions (US), Inc., 150 N. Dairy Ashford, Houston, TX 77079, USA

c Mechanical and Aerospace Engineering, University of California San Diego, 9500 Gilman Dr., La Jolla, CA 92093, USA

${ }^{1}$ Current address: Makai Ocean Engineering, Inc., PO Box 1206, Kailua, HI 96734

*Corresponding author. E-mail address: kasmith6@hawaii.edu

\section{Abstract}

Hanauma Bay Nature Preserve is a shallow bay ( $<30 \mathrm{~m}$ depth) on the island of O'ahu, Hawai' $i$, offshore of which tidal flow over deep ridge topography (500-1000 m depth) is known to generate semidiurnal frequency internal tides. A field experiment was conducted during March to June 2009 to determine whether the deep internal tides propagate shoreward to influence variability in temperature and currents in the bay environment. Temperature observations in the bay exhibit a diurnal cycle that is strongest near the surface (upper $10 \mathrm{~m}$ ) and is associated with solar heating. In early summer (May-June), as the upper mixed layer warms and a shallow seasonal thermocline develops, temperature fluctuations in deeper bay waters ( $>15 \mathrm{~m}$ depth) become dominated by large semidiurnal variations (up to $2.7^{\circ} \mathrm{C}$ ) that are attributed to the internal tide. These temperature drops caused by the internal tide occur consistently twice a day under summer stratification at 
depths as shallow as $15 \mathrm{~m}$, while smaller temperature drops (up to $1.8^{\circ} \mathrm{C}$ ) occur occasionally at $5 \mathrm{~m}$. Although semidiurnal band temperatures vary seasonally, semidiurnal band currents exhibit similar magnitudes in spring and summer. This suggests that the weak temperature fluctuations in spring are due to the bay residing entirely in the upper mixed layer at this time of year, while internal tide energy continues to influence currents. Observations made along a cross-shore/vertical transect at the center of the bay with an autonomous underwater vehicle highlight the structure of cold intrusions that fill a large portion of the bay as well as the relationship between temperature, salinity, chlorophyll, and backscatter. Near-bottom, advective heat flux estimates at the mouth of the bay indicate that the internal tide tends to advect cold water into the bay primarily on the northeast side of the bay entrance, with cold water outflow on the opposite side. The observations highlight the role of the internal tide along with seasonal changes in stratification in temperature variability in shallow ecosystems, particularly those close to generation sites.

Keywords: Internal waves; Internal tides; Cold intrusion; Coral reefs

\section{Introduction}

Internal waves at tidal frequency, or internal tides, are ubiquitous features in Hawaiian waters. Tidal flows over the Hawaiian ridge topography lead to energy conversion from the surface tide to the internal tide, particularly at semidiurnal frequencies (Egbert and Ray, 2001; Ray and Mitchum, 1996, 1997). The internal tide energy generated at the ridge mostly radiates away from the islands to the deep ocean 
(Carter et al., 2008; Merrifield et al., 2001; Merrifield and Holloway, 2002); however, locally the internal tide may lead to large vertical isotherm displacements (Eich et al., 2004; Hamilton et al., 1995; Hamilton, 1996), energetic coastal tidal currents (Eich et al., 2004; Alford et al., 2006), and turbulent mixing (Alford et al., 2006; Klymak et al., 2006; Rudnick et al., 2003). Around the main Hawaiian Islands, the internal tides are generated in the channels between the islands, notably off the north and, to a lesser extent, the south shores of O'ahu (Carter et al., 2008; Martini et al., 2007; Merrifield et al., 2001).

The internal tide on the south shore of O'ahu has been studied extensively with field observations (Alford et al., 2004; Eich et al., 2004; Hamilton, 1996; Martini et al., 2007) and numerical model simulations (Eich et al., 2004) in a region known as Mamala Bay (Figure 1). Together these studies describe predominantly westward propagating internal tides along the coast that originate at a generation site off the southeastern tip of the island near Makapu'u Point. The semidiurnal internal tides, with peak energy at the $\mathrm{M}_{2}$ tidal period (12.42 hours), are a constant presence over the narrow Mamala Bay shelf, with a detectable spring-neap modulation that reflects their coherence with the surface tide forcing, although nearly half of the semidiurnal band energy has been classified as incoherent with respect to the surface tide (Eich et al., 2004). Near the coast in shallow waters, Sevadjian et al. (2010) observed short duration bottom cold pulses associated with the $\mathrm{M}_{2}$ internal tide at the 40 $\mathrm{m}$ isobath in Mamala Bay, which occasionally reached the $12 \mathrm{~m}$ isobath.

Just west of Makapu'u Point and close to the main internal tide generation site lies Hanauma Bay (Figure 1), which the state of Hawai'i has designated as a Nature Preserve and Marine Life Conservation District due to its abundant coral reef habitat. The bay is semi-protected from winds and energetic winter swell events, and the circulation is 
irregular and not well described due to a lack of in situ measurements (Whittle, 2003). Internal tides have not been reported within Hanauma Bay, nor has the general thermal variability within the bay been characterized. The presence of a major internal tide generation site adjacent to Hanauma Bay has possible ramifications for the bay circulation that we aim to characterize.

The effects that internal waves, including internal tides, may have on coastal ecosystems have been investigated in previous studies and remain a topic of active research (e.g., Buerger et al., 2015; Gove et al., 2006; Leichter et al. 1996; Lucas et al., 2011; Pineda, 1991; Roder et al., 2010; Wolanski, 1988). Internal tides can cause regular upwelling of water from depth at coastal boundaries either by internal wave motion or by turbulent bore-like transport in the event that the wave breaks as it shoals into shallow water (Leichter et al., 1996; Pineda, 1991). Water transported from depth may carry with it suspended particles, such as larvae (Pineda, 1991), and is generally cooler (Leichter et al., 1996; Leichter and Miller, 1999), saltier (Leichter et al., 1996), more acidic (Roder et al., 2010), and richer in nutrients (Leichter et al., 2003) than the shallow water into which it intrudes. The influx of water from depth can have a complex range of effects on coral ecosystems (e.g., Al-Horani, 2005; Beach et al., 2006; Leichter et al., 2003; Palardy et al., 2005; Saxby et al., 2003; Sheppard, 2009; Smith et al., 2004; Wall et al., 2014; Wang et al., 2007; Wolanski, 1988).

In situ temperature and current sensors placed throughout Hanauma Bay over a nearly four-month period are used to characterize temperature variations in the bay during the transition from a deep, relatively cool mixed layer in spring to a warm mixed layer and shallow seasonal thermocline in summer. Our motivation for this study, which 
was to determine whether the proximity to a major semidiurnal internal tide generation site would lead to strong internal tide signatures within the bay, was verified by the presence of strong semidiurnal temperature variations in the lower layer during summer. The focus of the measurement array was on near-bottom temperature and currents due to sampling restrictions within this heavily utilized nature preserve; however, an autonomous underwater vehicle (AUV) survey was used to gather information on the full-depth structure of temperature, salinity, backscatter, and chlorophyll during a portion of the tidal cycle. Advective heat flux estimates suggest that the cold intrusions are not simply the result of a shoaling, two-dimensional, plane wave, as cold water near the bottom is transported into the bay on the northeast side of the entrance and exported on the opposite side, suggesting periodic pulses of cold water that enter and exit the bay.

\section{Methods}

\subsection{Study region}

Hanauma Bay is a $600 \mathrm{~m}$ by $1000 \mathrm{~m}$ embayment located on the southeastern shore of O'ahu, Hawai'i $\left(21.298^{\circ} \mathrm{N}, 157.6925^{\circ} \mathrm{W}\right)$ (Figure 1a). The bay formed within an extinct volcanic cone that is open to the ocean on the southeast side $\left(130^{\circ}\right.$ true north). The inner third of the bay is dominated by a fringing reef covered with turf and coralline algae, with isolated sand pockets that front a narrow sand beach (Figure 1b). The mid to outer part of the bay has aggregate and patch coral reef, with live coral cover in some areas of 50-90\%. The primary corals present are species of the genera Porites and Pocillopora, and calcareous red algae including Porolithon are also abundant (Easton and Olson, 1976). Two channels, Cable and Backdoor, cut across the fringing reef and connect the inner and outer 
bay. The bay reaches a maximum depth of 30 m near the entrance. Outside Hanauma, the shelf bathymetry is oriented east-west, with a steep ledge near the $100 \mathrm{~m}$ isobath. The shelf narrows in width at the headland just to the south of Hanauma Bay (Figure 1a).

\subsection{Instrumentation and sampling}

Currents, temperature, and wave energy inside Hanauma Bay were investigated using six Nortek acoustic Doppler current profilers (Aquadopps), two Nortek Acoustic Wave and Current profilers (AWACs), and a Hydroid REMUS-100 AUV. All current profilers recorded temperature and pressure. Instrument placement is shown in Figure $1 \mathrm{~b}$, and the instruments were configured as follows:

(a) Two 1 MHz Aquadopps were deployed at depths of $20 \mathrm{~m}$ and $15 \mathrm{~m}$ (AQ1, AQ2, respectively) in the bay's interior. Bins were set to $1 \mathrm{~m}$ with a blanking distance of $0.4 \mathrm{~m}$ and a horizontal accuracy after averaging of $0.009-0.016 \mathrm{~m} \mathrm{~s}^{-1}$. Three $2 \mathrm{MHz}$ Aquadopps (AQ3, AQ4, AQ5) were deployed at depths of 8 m, 7 m, and 5 m, respectively, and a fourth $2 \mathrm{MHz}$ Aquadopp was deployed in the Cable channel in 2$3 \mathrm{~m}$ of water (AQ6). Bins were set to $1 \mathrm{~m}$ for AQ3, AQ4, and AQ5 and $0.25 \mathrm{~m}$ for AQ6, with a blanking distance of $0.2 \mathrm{~m}$ and a horizontal accuracy after averaging of 0.02 $\mathrm{m} \mathrm{s}^{-1}$. All Aquadopps recorded 3-minute average currents every 5 minutes.

(b) Two $1 \mathrm{MHz}$ Nortek-AS AWAC Profilers (AW2, AW3) were deployed at depths of $20 \mathrm{~m}$ at either side of the bay entrance, recording 3-minute average currents every 5 minutes. Bin sizes were set to $1 \mathrm{~m}$ with a blanking distance of $0.4 \mathrm{~m}$ and horizontal accuracy after averaging of $0.012 \mathrm{~m} \mathrm{~s}^{-1}$. An additional AWAC (AW1) was 
programmed to capture directional wave information, which was used in a different study.

Due to low backscatter in the water column, all Aquadopps measured an unacceptable signal to noise ratio above mid-depth levels, which was manifested in the data as high frequency noise. This was not an issue for the Nortek AWACs due to their increased power output. Velocity data were converted to cross-shore and along-shore velocity components, where cross-shore velocity was defined as $50^{\circ}$ counterclockwise from true north based on the alignment of the bay topography. Cross-shore positive denotes normal shoreward into the bay, while positive alongshore denotes northeastward flow roughly parallel to the bay entrance $\left(40^{\circ}\right.$ clockwise from true north).

The REMUS-100 AUV was run for four hours on May 5, 2009 along a straight heading through the center of the bay (Figure 1b), performing 22 transects at a speed of 3.5 knots $(1.75 \mathrm{~m} / \mathrm{s})$, yo-yoing between the surface and near the bottom on the offshore leg and following the bed in the onshore direction. The AUV measured temperature and salinity at $16 \mathrm{~Hz}$ using a Seabird SBE-49 FastCAT CTD yielding an along-track resolution of roughly $10 \mathrm{~cm}$ for temperature and salinity. In addition, the AUV measured optical properties at $1 \mathrm{~Hz}$ (1.75 m along-track resolution) using a Wetlabs ECOpuck Triplet. The ECOpuck measures backscatter at wavelengths of $470 \mathrm{~nm}$ and $650 \mathrm{~nm}$ along with chlorophyll- $a$ fluorescence (470 nm excitation wavelength, $695 \mathrm{~nm}$ emission wavelength).

\subsection{Temperature variability and heat flux estimates}

A post-deployment dunk test, in which all temperature sensors were mounted to a single rack and deployed at uniform depth, revealed an offset in the temperature sensors 
which led to measurements that were biased 0.5 to $1^{\circ} \mathrm{C}$ higher at AW2, AW3, and AQ3 than at the other sensors. Because we are interested in variations in temperature over time rather than absolute temperatures, these offsets are not addressed.

Power density spectra were calculated for temperature, cross-shore velocity, and along-shore velocity for the spring and summer periods separately by subtracting the trend from the series then using seven 50\% overlapping 11-day Hanning windows. Temperature variability in the bay was also evaluated using metrics of 24-hour running temperature range (24-hour running maximum minus 24-hour running minimum) and standard deviation of temperature at given frequency bands. The standard deviations were calculated after the temperature time series were filtered for either semidiurnal $\left(1 / 8 \mathrm{~h}^{-1}\right.$ to $\left.1 / 16 \mathrm{~h}^{-1}\right)$ or diurnal frequencies $\left(1 / 20 \mathrm{~h}^{-1}\right.$ to $\left.1 / 28 \mathrm{~h}^{-1}\right)$ using a fourth-order band-pass Butterworth filter.

To create a metric for ecosystem exposure to cold water from depth, we used the temperature series to calculate "cool degree-hours per day." This was found by first removing short-term variability from the temperature with a fourth-order one-week lowpass Butterworth filter to create a "baseline" temperature series. Each time point where the temperature was lower than the baseline was considered a "cool" point, and the temperature differences between the baseline and the cool points were integrated over time in five-minute increments (the temperature sampling period) to calculate the cool degree-hours each day. For instance, if one day contained twelve time points that were each $1{ }^{\circ} \mathrm{C}$ below the low-pass baseline, that would result in a value of $1 \mathrm{cool}$ degree-hour per day. 
To compute tidal-band heat fluxes, the temperature and velocity data were bandpassed filtered using a fourth-order Butterworth filter to isolate energy at frequencies between $1 / 8 \mathrm{~h}^{-1}$ and $1 / 16 \mathrm{~h}^{-1}$ (semidiurnal) and between $1 / 20 \mathrm{~h}^{-1}$ and $1 / 28 \mathrm{~h}^{-1}$ (diurnal). Horizontal near-bottom heat fluxes $\left(\boldsymbol{F}^{\prime}, \mathrm{W} \mathrm{m}^{-2}\right)$ were calculated for both tidal bands at each location as

$$
\boldsymbol{F}^{\prime}=\rho c_{p} T^{\prime} \boldsymbol{V}^{\prime},
$$

where $\rho$ is density of seawater (here estimated as $1025 \mathrm{~kg} \mathrm{~m}^{-3}$ ), $c_{p}$ is specific heat of seawater $\left(3993 \mathrm{~J} \mathrm{~kg}^{-1}{ }^{\circ} \mathrm{C}^{-1}\right)$, and $T^{\prime}$ and $\boldsymbol{V}^{\prime}$ are the near-bottom temperature $\left({ }^{\circ} \mathrm{C}\right)$ and velocity vector $\left(\mathrm{m} \mathrm{s}^{-1}\right)$, respectively, both filtered for the relevant tidal-band variability. Mean values are removed by the tidal-band filter so that heat fluxes indicate temperatures either above or below the mean flowing into and out of the bay. A positive cross-shore heat flux corresponds to both onshore flow of warmer-than-average water and offshore flow of cooler-than-average water.

\section{Results}

\subsection{Temperature and current variability}

Temperatures in the bay depend on both depth and season. Bottom temperature variability at the outer, middle, and inner sections of the bay can be characterized by the measurements at AQ1 (20 m), AQ4 (7 m) and AQ6 (2 m), respectively. Temperatures were coolest $\left(\sim 23^{\circ} \mathrm{C}\right)$ throughout the bay over the first two months of the record, March and April ("spring") (Figure 2a). At the beginning of May, all temperatures began to increase due to seasonal heating, and they continued to rise through the end of the study period in mid-June to high values of $\sim 26^{\circ} \mathrm{C}$. A similar, rapid stratification change in May has been 
well documented at Station ALOHA (A Long-term Oligotrophic Habitat Assessment), north of the island of O'ahu $\left(22^{\circ} 45^{\prime} \mathrm{N} 158^{\circ} \mathrm{W}\right.$, Figure 1a inset) (Bingham and Lukas, 1996). Weak spring stratification gives way to stronger stratification during the May-June ("summer") period.

Daily temperature fluctuations in the bay changed from spring to summer both in magnitude and frequency. Temperature variability during the spring period was dominated at all locations by a diurnal frequency consistent with the daily heating and cooling cycle. During spring, diurnal temperature variations peaked at the shallow sensor closest to shore $\left(0.37^{\circ} \mathrm{C}\right.$ standard deviation at AQ6) and decreased with increasing depth $\left(0.08{ }^{\circ} \mathrm{C}\right.$ at AW3) (Figure 3a). The diurnal variation was higher in summer $\left(0.53{ }^{\circ} \mathrm{C}\right.$ standard deviation at $\mathrm{AQ} 6,0.18{ }^{\circ} \mathrm{C}$ at $\mathrm{AW} 3$ ) than in spring (Figure $3 \mathrm{~b}$ ). Semidiurnal temperature variability was relatively weak in the spring period (Figure 3c) but became dominant in summer at the deepest sensors (AW2, AW3, AQ1, AQ2) (Figure 3d). Semidiurnal temperature standard deviation at AQ6 increased from $0.15^{\circ} \mathrm{C}$ in spring to $0.19^{\circ} \mathrm{C}$ in summer, while at AQ1 (20 m depth) it increased from $0.08{ }^{\circ} \mathrm{C}$ to $0.36^{\circ} \mathrm{C}$. Spectra of temperature in the spring and summer at the deep (AQ1), mid-depth (AQ4), and shallow (AQ6) locations also illustrate the increasing semidiurnal temperature variability at depth in the summer (Figure 4). At AQ1, semidiurnal fluctuations became the dominant frequency in summer, while at $\mathrm{AQ} 4$, they gained in strength relative to the diurnal frequency but did not reach the same levels. At AQ6, however, energy at the diurnal frequency remained dominant through both time periods. This behavior is evident in a closer look at the temperature time series in May (Figure 2b): AQ6 (2 m) displays consistent diurnal variability associated with the daily heating cycle, while AQ1 (20 m) 
shows predominant semidiurnal variability, linked to the internal tide; the mid-depth sensor temperature variation is dominated by the daily heating cycle, but has occasional semidiurnal drops in temperature. Peaks at higher harmonic frequencies are especially prominent at the shallow (2 m) AQ6 sensor, presumably due to phase-locked asymmetries in the daily heating cycle.

In contrast with temperature, tidal currents did not change significantly between spring and summer (Figure 5). Bottom velocity values at the mouth of the bay (AW2 and AW3) varied between $\pm 0.2 \mathrm{~m} \mathrm{~s}^{-1}$ in the cross-shore direction. Bottom velocity magnitudes were lower at shallower sites, with the exception of AQ6 in the channel rip current, where cross-shore velocity magnitudes exceeded $0.4 \mathrm{~m} \mathrm{~s}^{-1}$. Semidiurnal bottom velocity amplitudes were greater than the diurnal amplitudes at the locations deeper than $10 \mathrm{~m}$, as seen in the tidal band ellipses (Figure 3). The current ellipses are similar for both seasons at all sensors. The spectra of bottom velocities (Figure 6) show a strong semidiurnal signal at $20 \mathrm{~m}$ (AQ1) in spring and summer. The spectra also show little change between seasons, with exceptions mainly in weaker velocity components. The same spectral analysis was repeated for the bottom velocities after subtracting out their tidal constituent fits, which were calculated using the t-tide Matlab toolbox (Pawlowicz et al., 2002). While these tidal fits included a portion of the currents caused by the internal tide in addition to the currents due to the surface tide, their removal still left the wider tidal-frequency band currents associated with the internal tide. The spectra from this analysis were similar to those in Figure 6 and showed no significant change between seasons at the diurnal and semidiurnal peaks, indicating that the internal tide currents are much less seasonal than the temperature. 


\subsection{Daily temperature range and cooling periods}

The 24-hour temperature range and cool degree-hours per day were high throughout the study period in the shallowest parts of the bay but increased from spring to summer in the deeper bay. Figure 7 shows the 24-hour temperature range and cool degreehours per day at AQ1 (20 m), AQ4 (7 m), and AQ6 (channel, $2 \mathrm{~m})$. 24-hour temperature range at AQ6 increased from spring to summer but was high during both, mostly over $1^{\circ} \mathrm{C}$ and often exceeding $2{ }^{\circ} \mathrm{C}$. Temperature range deeper in the bay was low during the spring (generally less than $1^{\circ} \mathrm{C}$ ), but increased in the summer. At AQ1, the summer temperature range at times exceeded $2{ }^{\circ} \mathrm{C}$, in some cases surpassing the temperature range at AQ6. Cool degree-hours per day (Figure 7b) were greatest at AQ6 for most of the study period. Spring values averaged $4.3 \mathrm{cool}$ degree-hours per day, while summer values averaged $6.2 \mathrm{cool}$ degree-hours per day. AQ1 and AQ4 recorded an average of 1.7 and 1.8 cool degree-hours per day, respectively, in the spring period. During the summer, AQ1 averaged $5.5 \mathrm{cool}$ degree-hours per day, while AQ4 averaged 3.4 cool degree-hours per day.

\subsection{Cross-shore heat flux}

Semidiurnal band-pass heat fluxes averaged over spring and summer months at the three 20 m depth locations at the mouth of the bay (AW2, AQ1, AW3) show that the cold intrusions evident in the temperature record did not enter uniformly across the mouth of the bay (Figure 8). Small semidiurnal heat flux values in the spring gave way to much larger magnitudes in May and June, but the direction of the flux varied by location. The semidiurnal cross-shore heat flux at AW3, on the north side of the bay mouth, was mostly 
offshore during summer months, representing the movement of cold water onshore and/or warm water offshore. In contrast, the semidiurnal cross-shore heat flux at AW2 at the south side of the bay mouth was largely onshore at that time, representing cold water moving offshore and/or warm water moving onshore. AQ1 in the center of the bay mouth, along with the other stations, did not show a significant positive or negative bias in semidiurnal heat flux. All diurnal-band heat fluxes were also small.

The summer semidiurnal heat flux at these locations can be related to the tidal climatologies of temperature and velocity. A two-week period was selected in May (May 417) over which temperature and velocity values were averaged with corresponding values at the same part of the $\mathrm{M}_{2}$ tidal phase. The averaged temperatures and velocities from different times in the $M_{2}$ phase are mapped in Figure 9. Temperatures were at their coolest at AW3 while tidal velocities pointed into the bay and warmest when they pointed offshore, both of which contributed to a negative heat flux in the cross-shore direction. The opposite was true at AW2.

\subsection{AUV transects}

The AUV transects show spatial temperature variation ranging approximately from the $25 \mathrm{~m}$ to $7 \mathrm{~m}$ isobaths in the bay over about a third of a tidal cycle, from local time $\sim 12: 00$, which was just prior to high tide, to $\sim 16: 00$, in the middle of ebb tide. The moored sensors show this as occurring during the warming portion of the semidiurnal cycle (Figure 10a). Figure 11 shows temperature over two sample flight paths of the AUV transects. When the transects began, the water column was largely unstratified and cold (Figure 11a). Over the course of the survey period, the cold water mass moved offshore, leaving the 
water column warmer and more stratified (Figure 11b). Daily heating may also have played a role in upper water column heating, given that the survey was in the early afternoon; however, the fact that similar warming is seen in the time series twelve hours later (Figure 10a) implies that the internal tidal fluctuation is the main factor in the temperature variations. Figures $11 \mathrm{~b}-\mathrm{d}$ show a top down view of temperature, salinity, and chlorophyll measured during the shoreward legs run by the AUV at an altitude of 3 meters above bottom (mab), plotted over time and distance to shore (upper part of the plot is deeper, $\sim 25 \mathrm{~m}$, and the lower part is shallower, $\sim 7 \mathrm{~m}$ ). Warming was accompanied by a decrease in salinity, consistent with higher density water moving out of the bay, evident in the nearbed AUV transect data (Figure $10 \mathrm{~b}$ and $\mathrm{c}$ ).

The AUV chlorophyll fluorescence measurements show chlorophyll concentrations

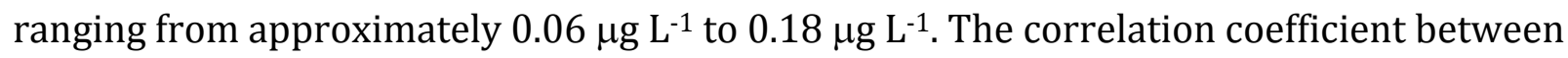
chlorophyll concentration and temperature measured through both space and time by the AUV was -0.65. Optical backscatter measured by the AUV was also negatively correlated with temperature. The $470 \mathrm{~nm}$ and $650 \mathrm{~nm}$ backscatter correlation coefficients with temperature were -0.55 and -0.62 , respectively. All correlations were found to be significantly different than zero $(\mathrm{p}<0.05)$ based on a Monte Carlo test in which synthetic time series were generated by phase randomization in the frequency domain. The relationships with temperature are evident both spatially and temporally; Figure 10 shows that overall warming over time at 3 mab was accompanied by an overall decrease in chlorophyll.

Despite the general warming trend in the AUV data, at approximately 14:30 the warming along the bottom ceased for about one hour, as colder water moved back into the 
bay (Figure 10b). This cooler water again receded, but not in a straightforward manner, which may indicate an internal wave entering the bay and breaking. The magnitude of this cold water intrusion $\left(0.5^{\circ} \mathrm{C}\right)$ is small compared to the semidiurnal temperature fluctuation $\left(>1.5^{\circ} \mathrm{C}\right)$ that day (Figure 10a). Furthermore, the cold intrusion is not evident at all of the moorings (Figure 10a), indicating that it affected only a portion of the bay. The cold water intrusion was accompanied by an increase in salinity, chlorophyll, and optical backscatter near the bottom (Figure 10). A Temperature-Salinity (TS) plot of the 3 mab data shows that readings before and after the beginning of the cold intrusion at 14:30 form two distinct TS curves (Figure 12).

\section{Discussion}

The semidiurnal internal tides generated off of Makapu'u Point, which have been observed in Mamala Bay (Alford et al., 2006; Eich et al., 2004; Hamilton et al., 1995; Martini et al., 2007), are evident in the temperature record in Hanauma Bay during the summer months of our study. The semidiurnal drops in bottom temperature observed at AW2, AW3, $\mathrm{AQ1}$, and $\mathrm{AQ2}$ are indicative of the semidiurnal internal tide traveling into the bay, consistently affecting temperature at depths as shallow as $15 \mathrm{~m}$ during the summer. Occasional semidiurnal temperature drops at stations AQ3, AQ4, and AQ5 show that the internal tide may sometimes affect temperatures as shallow as $5 \mathrm{~m}$ in the bay. The shallowest location, AQ6 in the Cable channel, displayed little evidence of semidiurnal temperature variability, indicating that the internal tide does not affect temperature in the surface layer shallower than $3 \mathrm{~m}$. Temperature variability here near the surface was consistently high in magnitude relative to the other locations but was dominated by an 
entirely different physical mechanism: diurnal fluctuations due to warming by the sun during daytime and cooling at night.

The semidiurnal temperature variation increased in the warm months likely due to stronger stratification and a thinner summer mixed layer. The negligible difference in the velocity record between spring and summer implies that horizontal currents associated with internal tides did not change significantly between seasons. Instead, semidiurnal internal tides influence temperature in the deep waters of the bay only in summer because it is during this period that there is a significant temperature gradient near those depths. Temperature depth profiles from Station ALOHA in February and May 2009 (data available at http://www.soest.hawaii.edu/HOT_WOCE/ftp.html) and from Mamala Bay in March and May 2013 (Comfort et al., 2015; data available at http://hahana.soest.hawaii.edu/cmoreswac/data/data.html) both show that the temperature change over the top $100 \mathrm{~m}$ of the water column increases from less than $0.5{ }^{\circ} \mathrm{C}$ in February/March to more than $2{ }^{\circ} \mathrm{C}$ in May. The similarities of the seasonal changes in the temperature profiles at the two sites in two different years imply that the water column offshore of Hanauma Bay likely exhibits similar features. By late June and July, the top $40 \mathrm{~m}$ of the water column in both data sets is uniformly warm, though temperature still drops $3^{\circ} \mathrm{C}$ in the top $100 \mathrm{~m}$. Therefore, as summer continues, semidiurnal fluctuations near the surface of the bay could lessen, but the deeper bay would likely continue to experience semidiurnal variability in temperature.

The single largest semidiurnal temperature drop observed was $2.7^{\circ} \mathrm{C}$ at AQ1 $(20 \mathrm{~m}$ isobath) in May. This temperature difference can be compared to the aforementioned temperature profiles from Mamala Bay, which is located approximately $20 \mathrm{~km}$ west of 
Hanauma Bay. In the Mamala Bay profile from May 22, 2013, the depth that was $2.7^{\circ} \mathrm{C}$ cooler than the $20 \mathrm{~m}$ depth temperature was $124 \mathrm{~m}$. This corresponds to a maximum isotherm displacement of over $100 \mathrm{~m}$, assuming that the offshore temperature profiles were similar. A more typical temperature drop of $1^{\circ} \mathrm{C}$ at $20 \mathrm{~m}$ depth would suggest a source depth of $70 \mathrm{~m}$. Considering that AQ1 had a summer average of 5.5 cool degree-hours per day, this could, for example, result from the site being exposed to water from $70 \mathrm{~m}$ depth for 5.5 hours per day. In spring, by contrast, the Mamala Bay temperature profile from March 1, 2013 shows that the upwelling of water from $70 \mathrm{~m}$ to $20 \mathrm{~m}$ would be expected to change the temperature by only $0.4{ }^{\circ} \mathrm{C}$. While the displacements are large considering the depth of the water, the cool water reaching the bay in summer is still only from the top of the thermocline.

Large changes in temperature in shallow reef habitats due to internal waves have been observed in such places as Conch Reef, Florida Keys (Leichter et al., 1996), Jarvis Island (Gove et al., 2006), and the Similan Islands (Roder et al., 2010). In the Florida Keys, the internal tide caused cold spikes over $5^{\circ} \mathrm{C}$ at $21 \mathrm{~m}$ depth in summer, though these events were rare, and even cold spikes of $2{ }^{\circ} \mathrm{C}$ occurred less frequently than once per day at this depth (Leichter and Miller, 1999). At Jarvis, cold spikes of $1-4{ }^{\circ} \mathrm{C}$ occurred at $\sim 12$-hour periods at $14 \mathrm{~m}$ depth, though these occurred in bursts of several days primarily when the Equatorial Undercurrent was shallow and strong. At the Similan Islands, large amplitude internal waves caused temperature drops up to $4^{\circ} \mathrm{C}$ at subtidal frequencies at $\sim 20 \mathrm{~m}$ depth (Roder et al., 2010). Internal tides have also been observed to affect temperature in shallow O'ahu waters before, but not in the manner seen in Hanauma Bay. Sevadjian et al. (2012) investigated cold pulses off the west shore of O'ahu at the $46 \mathrm{~m}, 20 \mathrm{~m}$, and $10 \mathrm{~m}$ 
isobaths, and one of their data collection periods overlapped in time (April and May 2009) with our study. The cold pulses on the west side averaged $0.5^{\circ} \mathrm{C}$ in magnitude over typical time periods of approximately three minutes and occurred more than ten times per day, on average. The frequency of the pulses and extent of propagation toward the shore increased at the beginning of May due to the strengthened stratification of the water column. Sevadjian et al. (2010) observed tidally driven cold intrusions at the $12 \mathrm{~m}$ isobath in Mamala Bay during summer 2007, though the intrusions were uncommon at this depth and generally caused temperature changes less than $0.5^{\circ} \mathrm{C}$ (Sevadjian, 2008; Sevadjian et al., 2010). The temperature drops observed in Hanauma Bay during the summer months were more regular, larger in magnitude, and longer in duration than these other O'ahu observations considering the depths affected, likely due to differences in local topography and position relative to generation sites.

Seasonal depth profiles of nutrients and $\mathrm{pH}$ from Mamala Bay and Station ALOHA (data from same sources as temperature profiles) give an indication of changes in those water properties that may accompany the fluctuations in temperature. Combined nitrate plus nitrite profiles from March and May 2013 at Mamala Bay's $110 \mathrm{~m}$ and $160 \mathrm{~m}$ isobaths increase from approximately $0.02 \mu \mathrm{mol} \mathrm{L}{ }^{-1}$ at $25 \mathrm{~m}$ depth (both March and May) to 0.03 $\mu \mathrm{mol} \mathrm{L}-1$ (March) or $0.10 \mu \mathrm{mol} \mathrm{L}^{-1}$ (May) at $45 \mathrm{~m}$ and to $0.14 \mu \mathrm{mol} \mathrm{L}^{-1}$ (March) or $0.47 \mu \mathrm{mol}$ $\mathrm{L}^{-1}$ (May) at $125 \mathrm{~m}$. Bottle profiles of $\mathrm{pH}$ taken from Station ALOHA in February, May, and July 2009 exhibit a slight decrease in $\mathrm{pH}$ over the top $120 \mathrm{~m}$ of the water column. The difference is most pronounced in July, with a 0.025 decrease in $\mathrm{pH}$ from $5 \mathrm{~m}$ below the surface to $100 \mathrm{~m}$ depth. Values of $\mathrm{pH}$ decrease more rapidly with depth starting at approximately $150 \mathrm{~m}$. Assuming the waters offshore of Hanauma Bay exhibit comparable 
seasonal profiles, intrusions entering Hanauma Bay due to the internal tide may be associated with increased nutrient concentrations. This would be similar to observations on the west side of the island, where water in cold pulses doubled the ambient nitrate concentrations (Sevadjian et al., 2012), as well as observations in other shoaling internal tide systems such as Conch Reef, Florida Keys (Leichter et al., 2003). However, while cool water upwelled by internal waves has been linked to significant drops in $\mathrm{pH}$ in places such as the Similan Islands (Schmidt et al., 2012), the profiles here indicate that it is unlikely the Hanauma Bay cold intrusions are accompanied by large changes in $\mathrm{pH}$.

The AUV data indicate that the cool water from depth entering the bay is associated with higher chlorophyll concentrations, as temperature and chlorophyll were negatively correlated over the course of the survey. This is consistent with profiles of chlorophyll in Mamala Bay, which found the chlorophyll maximum to be $60.8 \pm 13.8 \mathrm{~m}$ at the $100 \mathrm{~m}$ isobath (Comfort et al. 2015). Temperature was also negatively correlated with optical backscatter, showing that cooler water entering the bay may bring an increase in small, suspended particles. These particles could be non-biological, for instance if sediment is suspended as the internal tide propagates up the slope, but they may also be phytoplankton and/or zooplankton transported by the internal tide. Shoreward transport of plankton and larvae by internal waves has been observed on O'ahu's west side, where Sevadjian et al. (2012) found that the water associated with cold pulses had increased chlorophyll fluorescence, phytoplankton concentrations, and acoustic backscatter, as well as at other nearshore locations (e.g., Pineda 1991).

The AUV profiles also suggest that, in addition to the large-scale temperature variations that occur at semidiurnal frequency, occasional smaller internal waves may 
enter the bay and break, leading to mixing. The shift in the TS curves of the near-bottom water suggests that the cold water intrusion starting at approximately 14:30 caused mixing with water from above, which led to fresher water near the bottom for the rest of the survey (Figure 12). This intrusion had limited spatial range in the bay and was approximately $0.5^{\circ} \mathrm{C}$ in magnitude. With only the 4 hours of AUV profile data, it cannot be determined how common this type of intrusion is in Hanauma Bay. In any case, the intrusions are small in scale relative to the variation due to the regular semidiurnal internal tide that affects the deeper waters of the bay.

The opposing cross-shore tidal flows at the northeast (AW3) and southwest (AW2) sides of the bay mouth suggest that cold water at tidal period tends to enter the bay on the northeast side and exit on the southwest side. This creates a picture of the cold water associated with the semidiurnal internal tide washing into the bay on the northeastern side, then curving in a counterclockwise direction and exiting on the southwestern side. Such behavior is consistent with the generation of the internal tide over the ridge off Makapu'u Point to the east. The fact that the internal tide is associated with a heat flux indicates that the cold intrusion is not simply a plane wave washing in and out of the bay, affecting the bottom layer; it exhibits horizontal asymmetry. With only bottom temperature measured, the vertical profile of heat flux over time is unavailable, so the extent of the water column affected by the heat flux associated with the internal tide is unknown.

\section{Conclusions}

Semidiurnal internal tides generated over the ridge offshore of Makapu'u Point on the southeast corner of the island of $\mathrm{O}$ 'ahu propagate into the shallow coral reef habitat of 
Hanauma Bay. In the spring (and likely winter as well), the energy associated with these internal tides causes fluctuations in currents but is accompanied by little change in temperature, due to the fact that the upper water column is well mixed. In summer, however, intensified surface stratification allows the internal tide to cause temperature drops as large as $2.7^{\circ} \mathrm{C}$ in the bay. Semidiurnal temperature drops due to the internal tide occur consistently twice a day throughout May and June in $15 \mathrm{~m}$ water and are even present occasionally at depths as shallow as $5 \mathrm{~m}$.

Cold pulses due to internal waves have been observed at other locations around O'ahu (Sevadjian et al., 2010 and 2012), but our observations in Hanauma Bay are distinct from previous observations, having a regular semidiurnal period and greater magnitudes at shallower depths. These notable characteristics are likely due to the close proximity and orientation of the bay relative to the generation site. Given the numerous hot spots of internal tide generation over the Hawaiian Ridge (Rudnick et al., 2003), nearshore systems with similar temperature variations may exist throughout the island chain. While the effects internal tides may have on coral reef ecosystems are complex, the observed presence of large, regular cold intrusions during the warmest time of year might benefit coral reef systems by offering corals relief from the elevated temperatures that can lead to coral bleaching (Hoegh-Guldberg and Smith, 1989; Wall et al., 2014). Therefore, understanding how physical mechanisms such as internal tides behave in nearshore island settings such as this one is an important part of predicting the vulnerabilities of coral reef ecosystems.

\section{Acknowledgements}


We thank Chris Kontoes for help with sensor deployment and recovery, and Christina Comfort, Sarah Searson, and C-MORE Grant EF04-2459 for Mamala Bay profile data. We also thank two anonymous reviewers whose helpful comments substantially improved this manuscript. Station ALOHA data were obtained through Hawaii Ocean Time-series observations supported by the U.S. National Science Foundation (current grant number OCE-0926766). This work was funded by University of Hawaii Sea Grant Project ID 337. 


\section{References}

Al-Horani, F. A. 2005. Effects of changing seawater temperature on photosynthesis and calcification in the scleractinian coral Galaxea fascicularis, measured with $\mathrm{O}_{2}, \mathrm{Ca}^{2+}$ and pH microsensors. Sci. Mar. 69: 347-354.

Alford, M. H., M. C. Gregg, and M. A. Merrifield. 2006. Structure, propagation, and mixing of energetic baroclinic tides in Mamala Bay, Oahu, Hawaii. J. Phys. Oceanogr. 36: 9971018.

Beach, K. L., L. Walters, and H. Borgeas. 2006. Irradiance and nutrient limitation of Dicytota spp. populations on Conch Reef, Florida Keys, USA. J. Exp. Mar. Bio. Ecol. 329: 101112, doi:10.1016/j.jembe.2005.08.010

Bingham, F.M. and R. Lukas. 1996. Seasonal cycles of temperature, salinity and dissolved oxygen observed in the Hawaii Ocean Time-series. Deep-Sea Res. II, 43(2-3): 199213.

Buerger, P., G. M. Schmidt, M. Wall, C. Held, C. Richter. 2015. Temperature tolerance of the coral Porites lutea exposed to simulated large amplitude internal waves (LAIW). J. Exp. Mar. Biol. Ecol. 471: 232-239. doi:10.1016/j.jembe.2015.06.014

Carter, G. S., M. A. Merrifield, J. M. Becker, K. Katsumata, M. C. Gregg, D. S. Luther, M. D. Levine, T. J. Boyd, and Y. L. Firing. 2008. Energetics of $\mathrm{M}_{2}$ Barotropic-to-Baroclinic Tidal Conversion at the Hawaiian Islands. J. Phys. Oceanogr. 38: 2205-2223, doi:10.1175/2008JPO3860.1

Comfort, C. M., M. A. McManus, S. J. Clark, D. M. Karl, and C. E. Ostrander. 2015. Environmental properties of coastal waters in Mamala Bay, Oahu, Hawaii, at the 
future site of a seawater air conditioning outfall. Oceanography 28(2): 230-239, http://dx.doi.org/10.5670/oceanog.2015.46.

Easton, W. H., E. A. Olson. 1976. Radiocarbon profile of Hanauma Reef, Oahu, Hawaii. Geol. Soc. Am. Bull. 87: 711-719.

Egbert, G. D. and R. D. Ray. 2001. Estimates of $\mathrm{M}_{2}$ tidal energy dissipation from TOPEX/Poseidon altimeter data. J. Geophys. Res. 106: 22475-22502.

Eich, M. L., M. A. Merrifield, and M. H. Alford. 2004. Structure and variability of semidiurnal internal tides in Mamala Bay, Hawaii. J. Geophys. Res. 109: 1-13, doi:10.1029/2003JC002049

Gove, J. M., M. A. Merrifield, and R. E. Brainard. 2006. Temporal variability of current-driven upwelling at Jarvis Island. J. Geophys. Res. 111: 1-10, doi:10.1029/2005JC003161

Hamilton, P., J. J. Singer, and E. Waddell. 1995. Ocean current measurements, final report, Mamala Bay Study, project MB-6, Mamala Bay Study Comm., Honolulu, Hawaii. Hamilton, P. 1996. Observations of tidal circulation in Mamala Bay, Hawaii, paper presented at North American Water and Environment Congress. Am. Soc. of Civil Eng., Anaheim, Calif.

Hoegh-Guldberg, O., and G. J. Smith. 1989. The effect of sudden changes in temperature, light and salinity on the density and export of zooxanthellae from the reef corals Stylophora pistillata and Seriatopora hystrix. J. Exp. Mar. Bio. Ecol. 129: 279-303.

Klymak, J. M., J. N. Moum, J. D. Nash, E. Kunze, J. B. Girton, G. S. Carter, C. M. Lee, T. B. Sanford, and M. C. Gregg. 2006. An Estimate of Tidal Energy Lost to Turbulence at the Hawaiian Ridge. J. Phys. Oceanogr. 36: 1148-1164, doi:10.1175/JP02885.1 
Leichter, J. J., and S. J. Genovese. 2006. Intermittent upwelling and subsidized growth of the scleractinian coral Madracis mirabilis on the deep fore-reef slope of Discovery Bay, Jamaica. Mar. Ecol. Prog. Ser. 316: 95-103, doi:10.3354/meps316095

Leichter, J. J., and S. L. Miller. 1999. Predicting high-frequency upwelling: Spatial and temporal patterns of temperature anomalies on a Florida coral reef. Cont. Shelf Res. 19: 911-928, doi:10.1016/S0278-4343(99)00004-7

Leichter, J. J., H. L. Stewart, and S. L. Miller. 2003. Episodic nutrient transport to Florida coral reefs. Limnol. Oceanogr. 48: 1394-1407, doi:10.4319/lo.2003.48.4.1394

Leichter, J. J., S. R. Wing, S. L. Miller, and M. W. Denny. 1996. Pulsed delivery of subthermocline water to Conch Reef (Florida Keys) by internal tidal bores. Limnol. Oceanogr. 41: 1490-1501, doi:10.4319/lo.1996.41.7.1490

Lucas, A. J., P. J. S. Franks, C. L. Dupont. 2011. Horizontal internal-tide fluxes support elevated phytoplankton productivity over the inner continental shelf. Limnol. Oceanogr.-Fluids Envir. 1:56-74.

Martini, K. I., M. H. Alford, J. D. Nash, E. Kunze, and M. A. Merrifield. 2007. Diagnosing a partly standing internal wave in Mamala Bay, Oahu. Geophys. Res. Lett. 34: 1-5, doi:10.1029/2007GL029749

Merrifield, M. A., and P. E. Holloway. 2002. Model estimates of $M_{2}$ internal tide energetics at the Hawaiian Ridge. J. Geophys. Res. 107: 1-12, doi:10.1029/2001JC000996

Merrifield, M. A., P. E. Holloway, and T. M. S. Johnston. 2001. The generation of internal tides at the Hawaiian Ridge. Geophys. Res. Lett. 28: 559, doi:10.1029/2000GL011749 
Palardy, J. E., A. G. Grottoli, and K. A. Matthews. 2005. Effects of upwelling, depth, morphology and polyp size on feeding in three species of Panamanian corals. Mar. Ecol. Prog. Ser. 300: 79-89, doi:10.3354/meps300079

Pawlowicz, R., B. Beardsley, and S. Lentz. 2002. Classical tidal harmonic analysis including error estimates in MATLAB using T_TIDE. Computers and Geosciences 28: 929-937.

Pineda, J. 1991. Predictable upwelling and the shoreward transport of planktonic larvae by internal tidal bores. Science 253: 548-551, doi:10.1126/science.253.5019.548

Ray, R. D. and G. T. Mitchum. 1996. Surface manifestation of internal tides generated near Hawaii. Geophys. Res. Lett. 23: 2101-2104.

Ray, R. D. and G. T. Mitchum. 1997. Surface manifestation of internal tides in the deep ocean: Observations from altimetry and island gauges. Prog. Oceanogr. 40: 135-162.

Roder, C., L. Fillinger, C. Jantzen, G. M. Schmidt, S. Khokiattiwong, and C. Richter. 2010. Trophic response of corals to large amplitude internal waves. Mar. Ecol. Prog. Ser. 412: 113-128, doi:10.3354/meps08707

Rudnick, D. L., T. J. Boyd, R. E. Brainard, G. S. Carter, D. Gary, M. C. Gregg, P. E. Holloway, J. M. Klymak, E. Kunze, C. M. Lee, M. D. Levine, D. S. Luther, J. P. Martin, M. A. Merrifield, J. N. Moum, J. D. Nash, R. Pinkel, L. Rainville, T. B. Sanford, and G. D. Egbert. 2003. From Tides to Mixing along the Hawaiian Ridge. Science 301: 355-357.

Saxby, T., W. C. Dennison, and O. Hoegh-Guldberg. 2003. Photosynthetic response of the coral Montipora digitata to cold temperature stress. Mar. Ecol. Prog. Ser. 248:85-97.

Schmidt, G. M., N. Phongsuwan, C. Jantzen, C. Roder, S. Khokittiawong, and C. Richter. 2012. Coral community composition and reef development at large amplitude internal 
wave affected coral reefs in the Andaman Sea. Mar. Ecol. Prog. Ser. 456: 113-126. doi:10.3354/meps09682

Sevadjian, J. C. 2008. The effects of physical structure and processes on thin zooplankton layers in Mamala Bay, Hawai'i. M.S. thesis. University of Hawai'i at Mānoa, HI.

Sevadjian, J. C., M. A. McManus, and G. Pawlak. 2010. Effects of physical structure and processes on thin zooplankton layers in Mamala Bay, Hawaii. Mar. Ecol. Prog. Ser. 409: 95-106, doi:10.3354/meps08614

Sevadjian, J. C., M. A. McManus, K. J. Benoit-Bird, and K. E. Selph. 2012. Shoreward advection of phytoplankton and vertical re-distribution of zooplankton by episodic nearbottom water pulses on an insular shelf: Oahu, Hawaii. Cont. Shelf Res. 1-49, doi:10.1016/j.csr.2012.09.006

Sheppard, C. 2009. Large temperature plunges recorded by data loggers at different depths on an Indian Ocean atoll: comparison with satellite data and relevance to coral refuges. Coral Reefs 28: 399-403, doi:10.1007/s00338-009-0476-x

Smith, J. E., C. M. Smith, P. S. Vroom, K. L. Beach, and S. L. Miller. 2004. Nutrient and growth dynamics of Halimeda tuna on Conch Reef, Florida Keys: Possible influence of internal tides on nutrient status and physiology. Limnol. Oceanogr. 49: 1923-1936, doi:10.4319/lo.2004.49.6.1923

Wall, M., L. Putchim, G. M. Schmidt, C. Jantzen, S. Khokiattiwong, and C. Richter. 2014. Largeamplitude internal waves benefit corals during thermal stress. Proc. R. Soc. B 282: 20140650. doi:10.1098/rspb.2014.0650 
Wang, Y.-H., C.-F. Dai, and Y.-Y. Chen. 2007. Physical and ecological processes of internal waves on an isolated reef ecosystem in the South China Sea. Geophys. Res. Lett. 34: 1-7, doi:10.1029/2007GL030658

Whittle, A. 2003. Ecology, abundance, diversity, and distribution of larval fishes and schindleriidae at two sites on Oahu, Hawaii. PhD dissertation. University of Hawai'i at Mānoa, HI.

Wolanski, E., E. Drew, K. M. Abel, and J. O’Brien. 1988. Tidal jets, nutrient upwelling and their influence on the productivity of the alga Halimeda in the Ribbon Reefs, Great Barrier Reef. Estuar. Coast. Shelf Sci. 26: 169-201. 


\section{Figures}

Figure 1. a. Map of eastern O'ahu with $50 \mathrm{~m}$ depth contours. Inset shows location of Station ALOHA (circle) in relation to the island. Rectangle indicates Hanauma Bay region shown in (b). b. Aerial view of Hanauma Bay. Instrument positions and AUV track (black) are overlaid with 5 m contour lines (white). Note the rip channel at AQ6.

Figure 2. a. Temperature record from AQ1 at $20 \mathrm{~m}$ (blue), AQ4 at $7 \mathrm{~m}$ (black) and AQ6 at 2 $\mathrm{m}$ (red). The beginning of the record is characterized by weak temperature fluctuations at depth (AQ1, AQ5) compared to the large deviations at the surface (AQ6). Later in the record, all instruments show a warming trend and a seasonal stratification develops, accompanied by large fluctuations at AQ1. The black box indicates the time frame shown in greater detail in (b).

b. AQ1 shows consistent semidiurnal variability in May, while AQ6 shows consistent diurnal variability. AQ4 displays diurnal variability with occasional semidiurnal variability.

Figure 3. Standard deviation of temperature $\left({ }^{\circ} \mathrm{C}\right)$ and bottom current ellipses for diurnal and semidiurnal tidal bands in March-April (Spring) and May-June (Summer), 2009.

Figure 4. Temperature spectra at AQ1 (20 m), AQ4 (7 m), and AQ6 (2 m) from March-April (black) and May-June (gray). Vertical bar indicates 95\% confidence interval. March-April shows diurnal as the dominant frequency at all three locations. In May-June, the 
semidiurnal frequency dominates at AQ1, grows in relative strength but does not surpass the diurnal at $\mathrm{AQ4}$, and remains weaker than the diurnal at AQ6.

Figure 5. Bottom cross-shore currents $\left(\mathrm{m} \mathrm{s}^{-1}\right)$ over the course of the study. Note that AW2, AW3, and AQ6 have a different vertical scale than the other sensors. Cross-shore currents are representative of the variability in velocity.

Figure 6. Along-shore and cross-shore velocity spectra for AQ1 (20 m), AQ4 (7 m), and AQ6 (2 m) in March-April (black) and May-June (gray) time periods. Vertical bar indicates 95\% confidence interval.

Figure 7. a. 24-hour running temperature range at AQ1 (bay mouth), AQ4 (7 m) and AQ6 (2 m). b. Cool degree-hours per day (degrees below 7-day low-pass filtered baseline, integrated over each day) at AQ1, AQ4, and AQ6.

Figure 8. Semidiurnal-band heat flux $\left(\mathrm{kW} \mathrm{m}^{-2}\right)$ at $\mathrm{AQ1}, \mathrm{AW}$, and AW3 averaged over March-April and May-June seasons. Other stations did not exhibit significant trends.

Figure 9. Average velocity and temperature anomalies from May 4 - May 18, at various times throughout the 12.42-hour $\mathrm{M}_{2}$ tidal cycle.

Figure 10. a. Temperature at AQ1, 2, 3, 4, 5, and 6, with gray box representing time period (local time) of AUV transects. Dashed lines indicate the times of transects shown in Figure 
11. b. Temperature from the AUV transects at $\sim 3 \mathrm{~m}$ above bottom, over time. The upper part of the plot is deep water $(\sim 25 \mathrm{~m})$ and the lower part is shallow $(\sim 7 \mathrm{~m})$. c. Same as $(\mathrm{b})$, for salinity. d. Same as (b), for chlorophyll.

Figure 11. Temperature readings (color) and inferred temperature contours (black) from a. early AUV transect at 12:32 local time (just before high tide), and b. late AUV transect at 15:02 local time (middle of ebb tide).

Figure 12. Temperature-Salinity plot from $3 \mathrm{~m}$ above bottom (mab) AUV data, where black and gray dots indicate data before and after 14:30, respectively. Early in the AUV run, TS observations tended toward the bottom right of the plot, with subsequent $3 \mathrm{mab}$ observations becoming warmer and fresher. After the cold intrusion at 14:30, the readings followed a different TS curve, indicative of mixing. High temperature observations in this period are from the shallowest points in the transect (depth $<10 \mathrm{~m}$ ), likely due to midafternoon warming in the surface layer. 

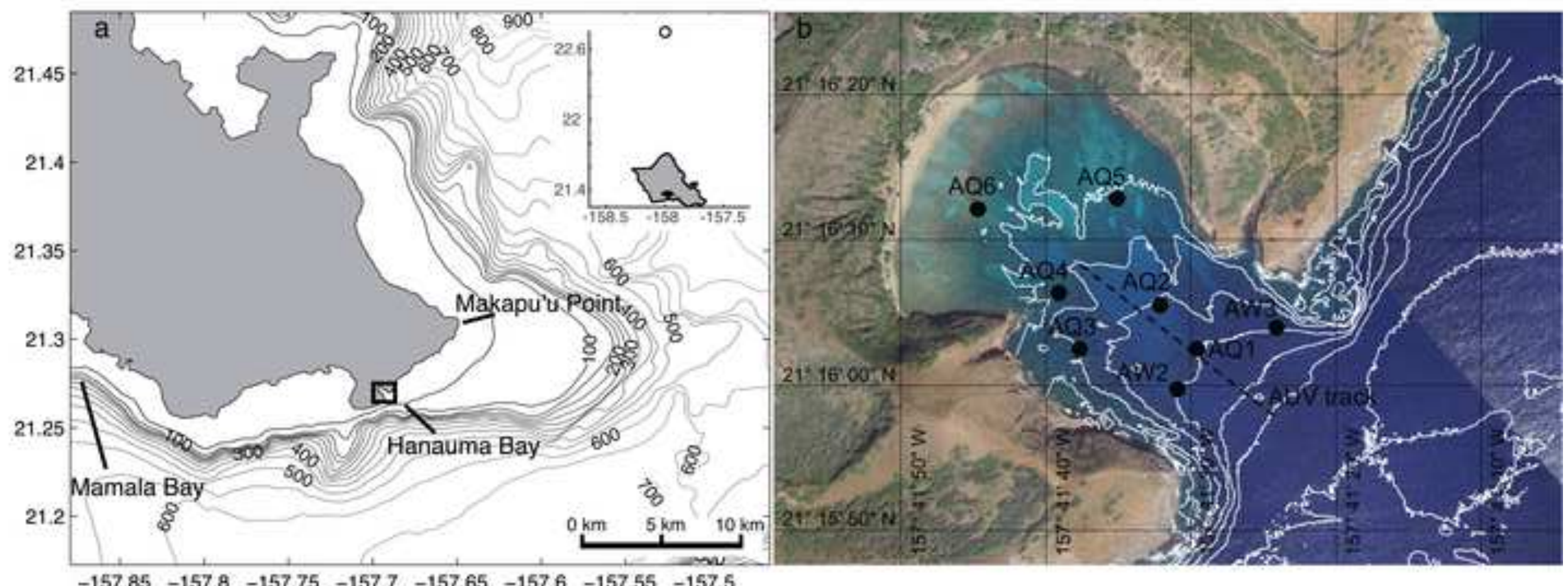
Figure
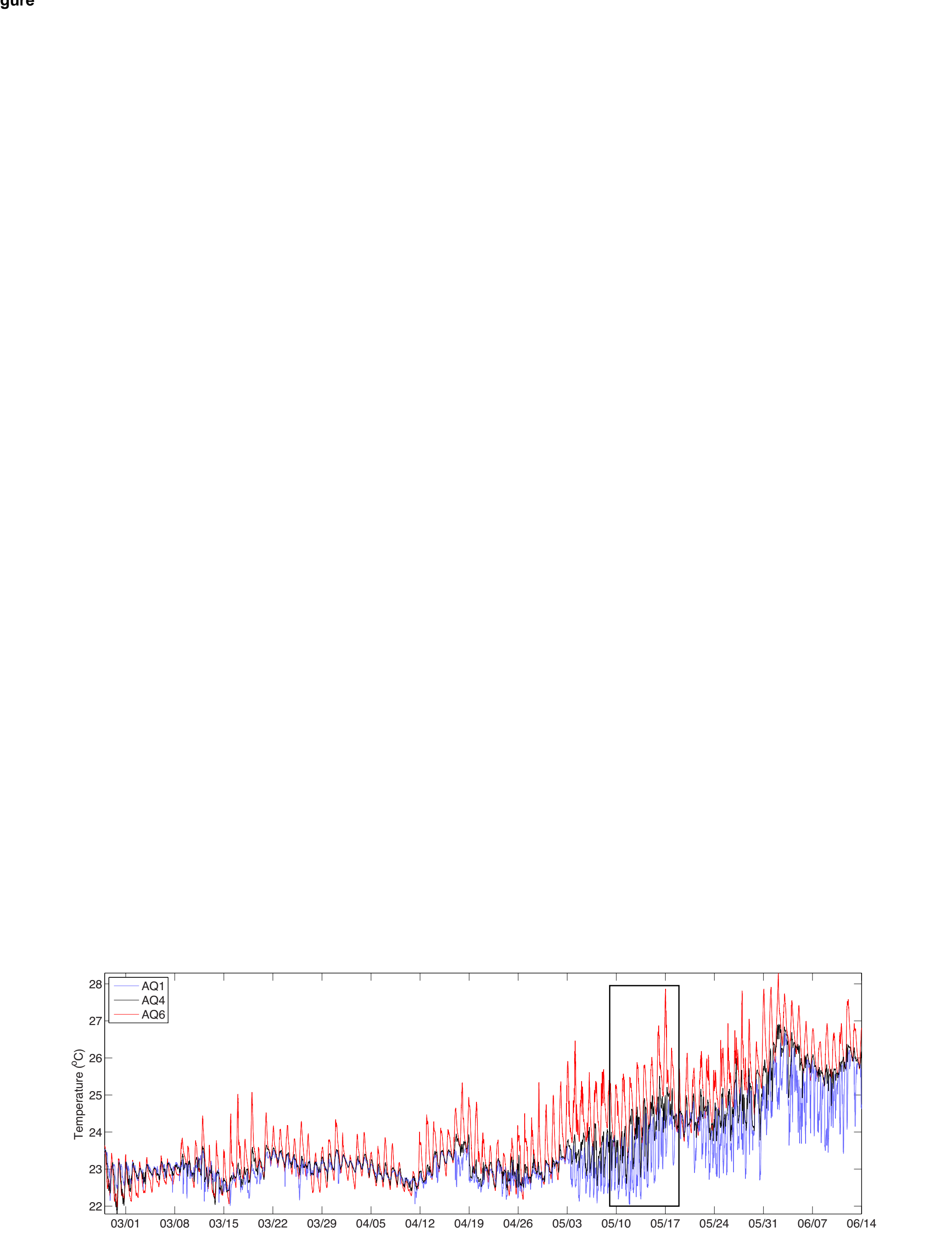
Temperature at AQ1, AQ4, AQ6

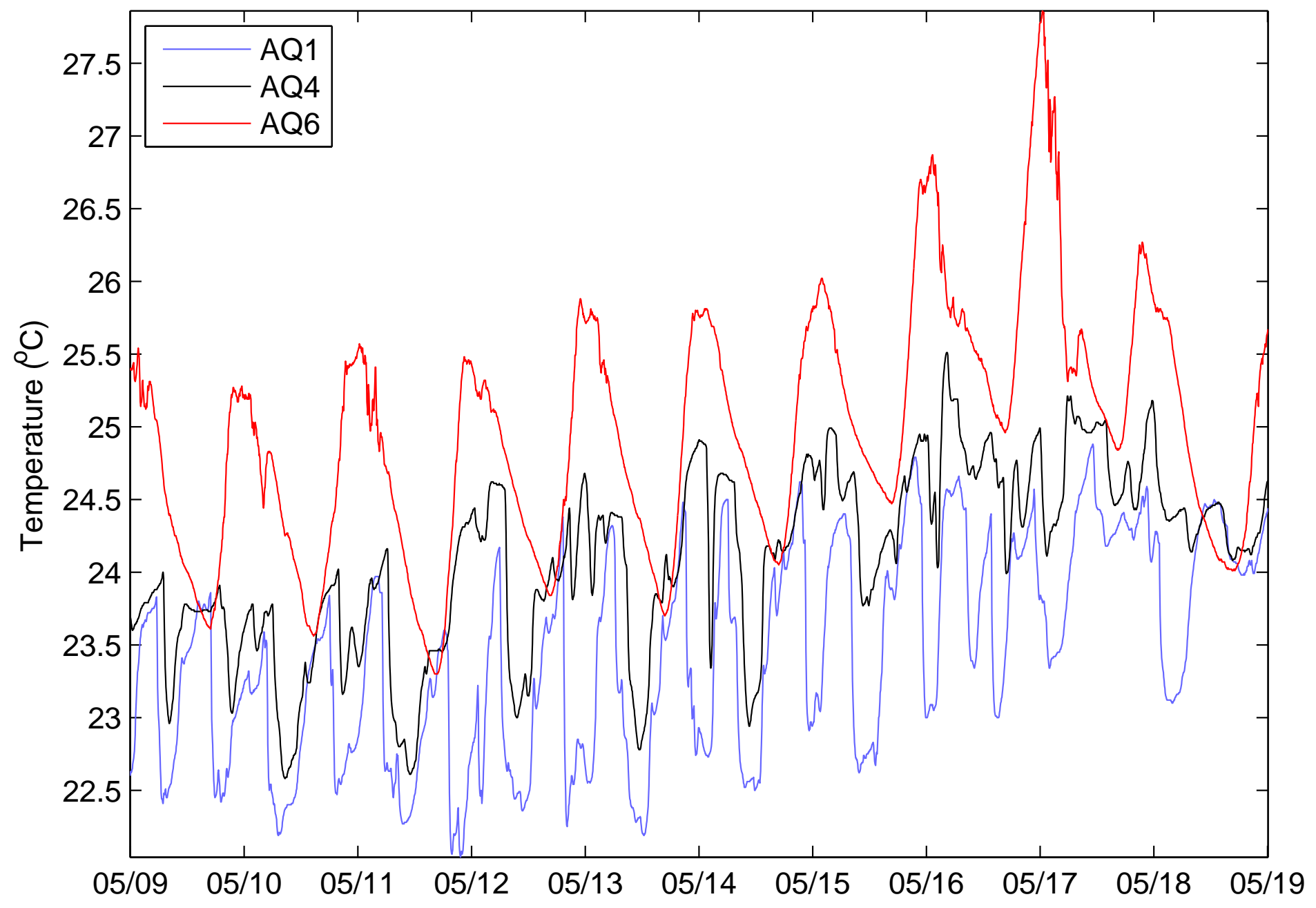



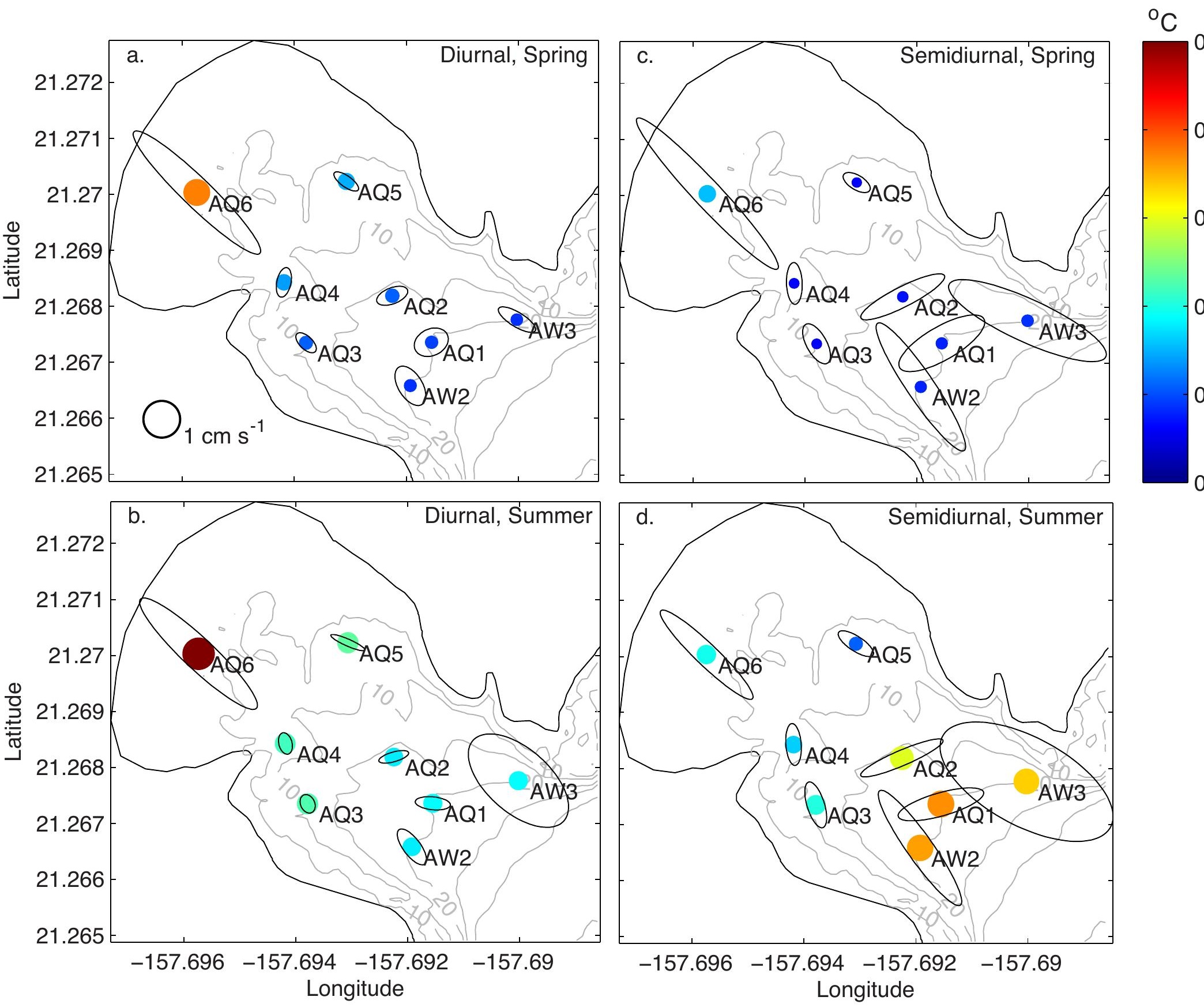
Figure

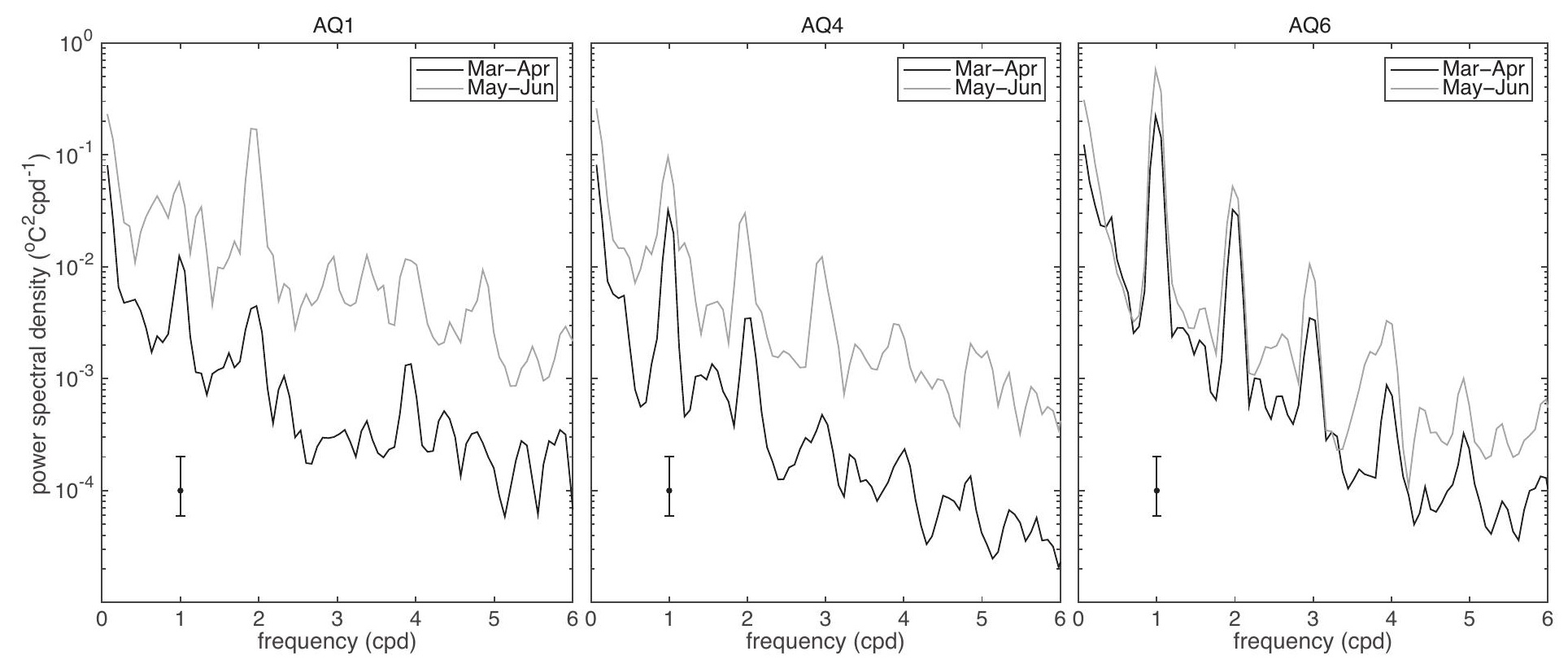




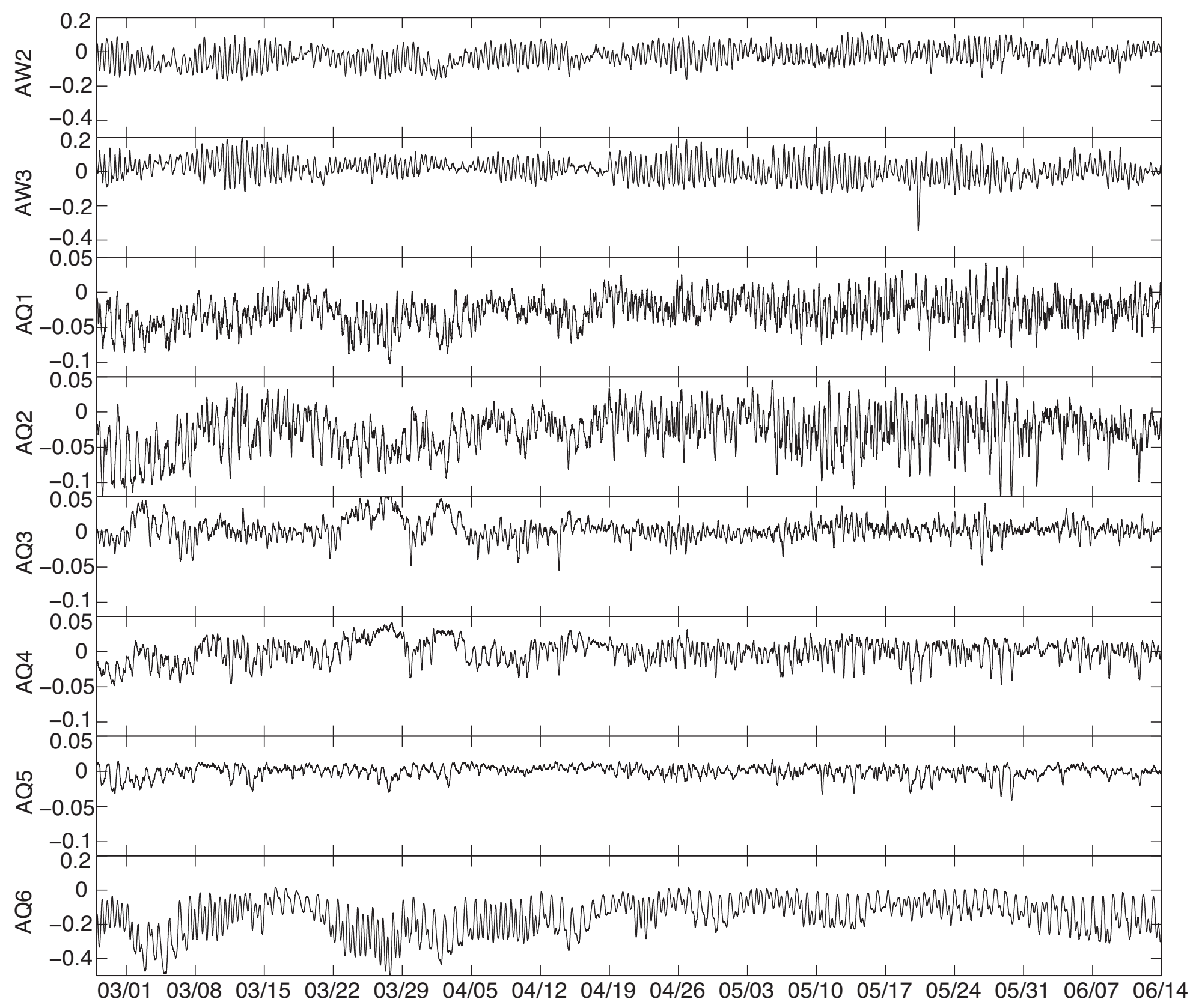


Figure

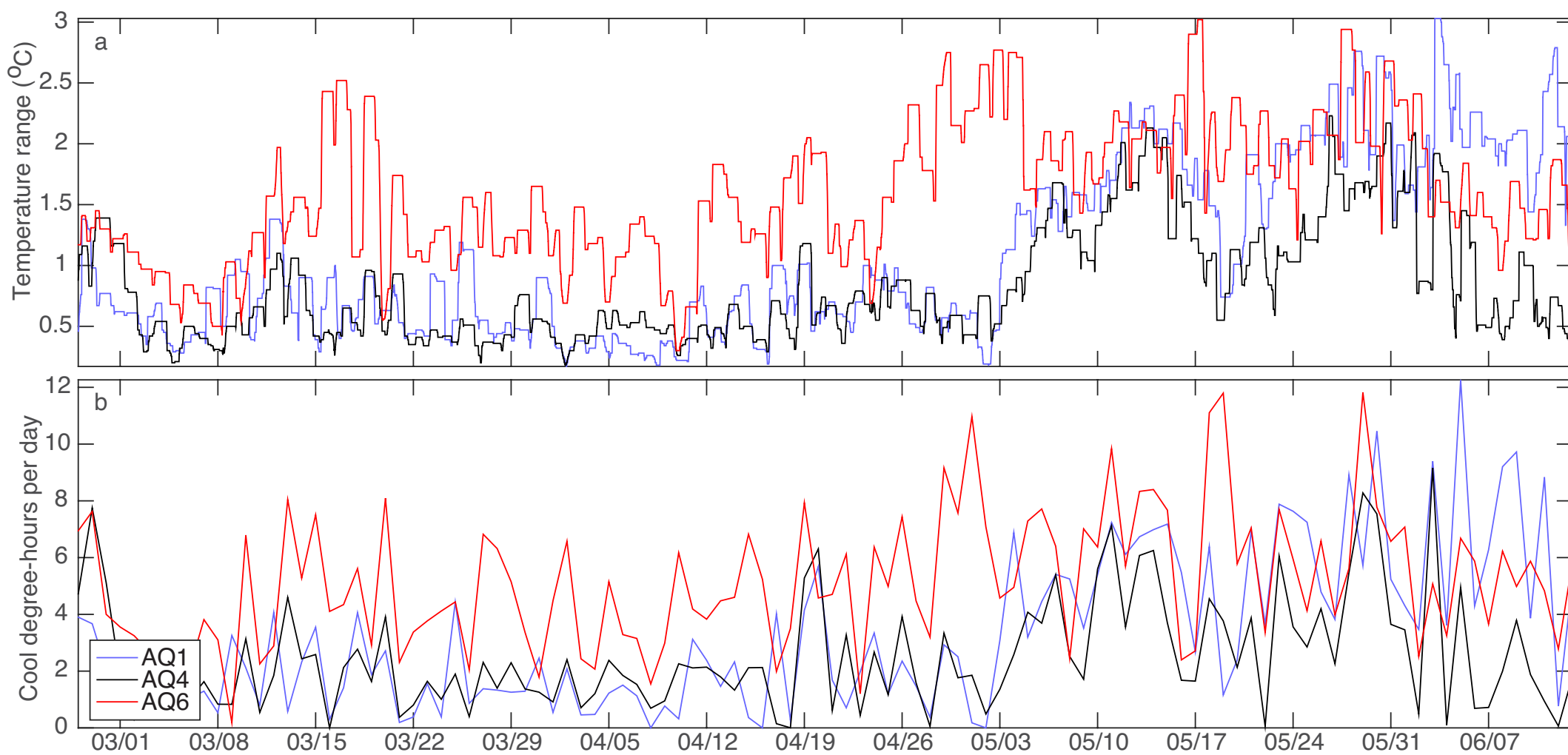




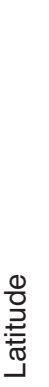
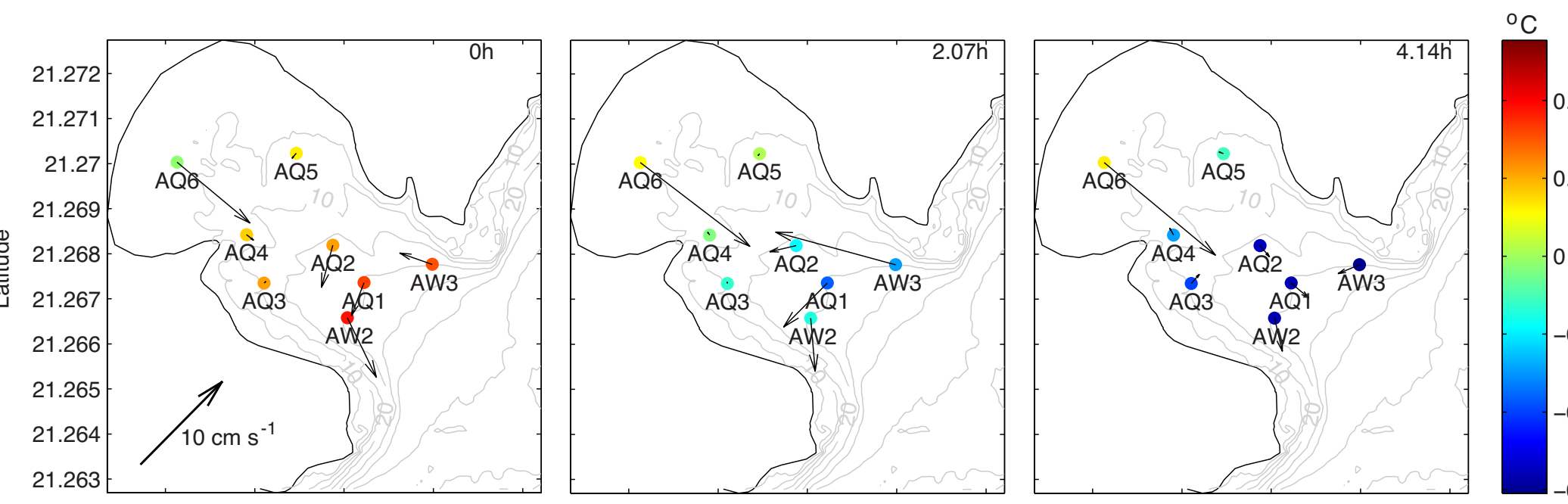


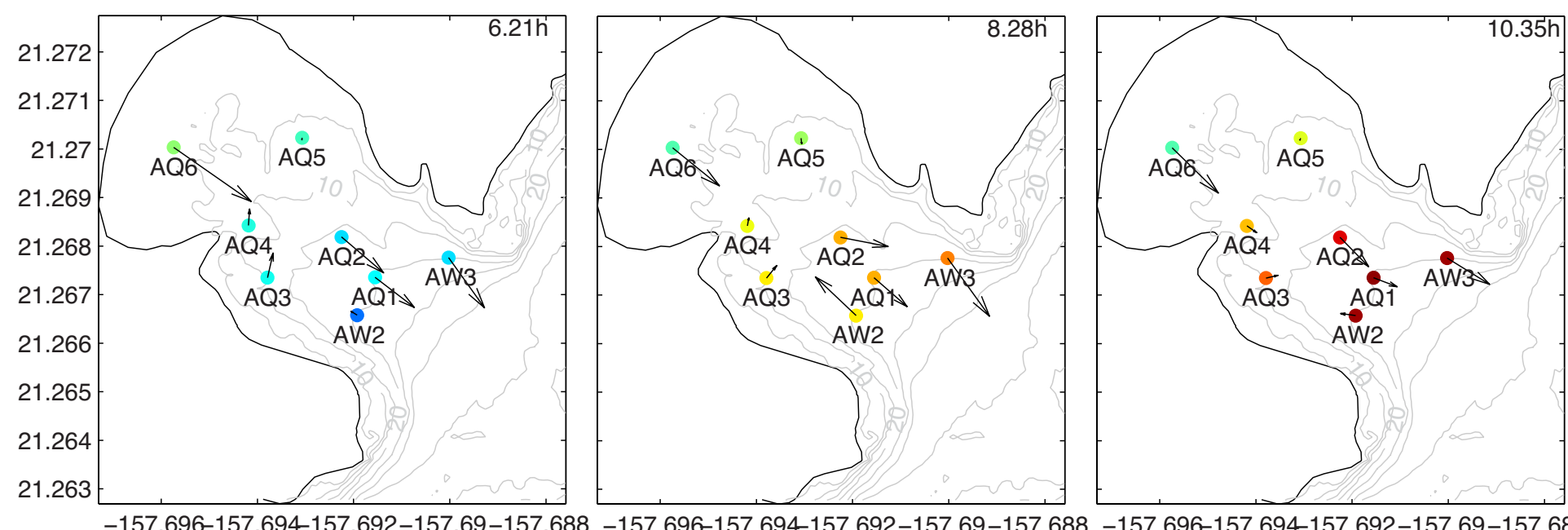

$$
\begin{aligned}
& .694-15 / .692-15 / .69-15 / .688-15 / .696-15 / .694-15 / .692-15 \\
& \text { Longitude }
\end{aligned}
$$



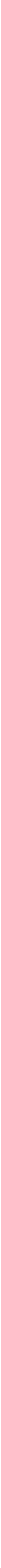


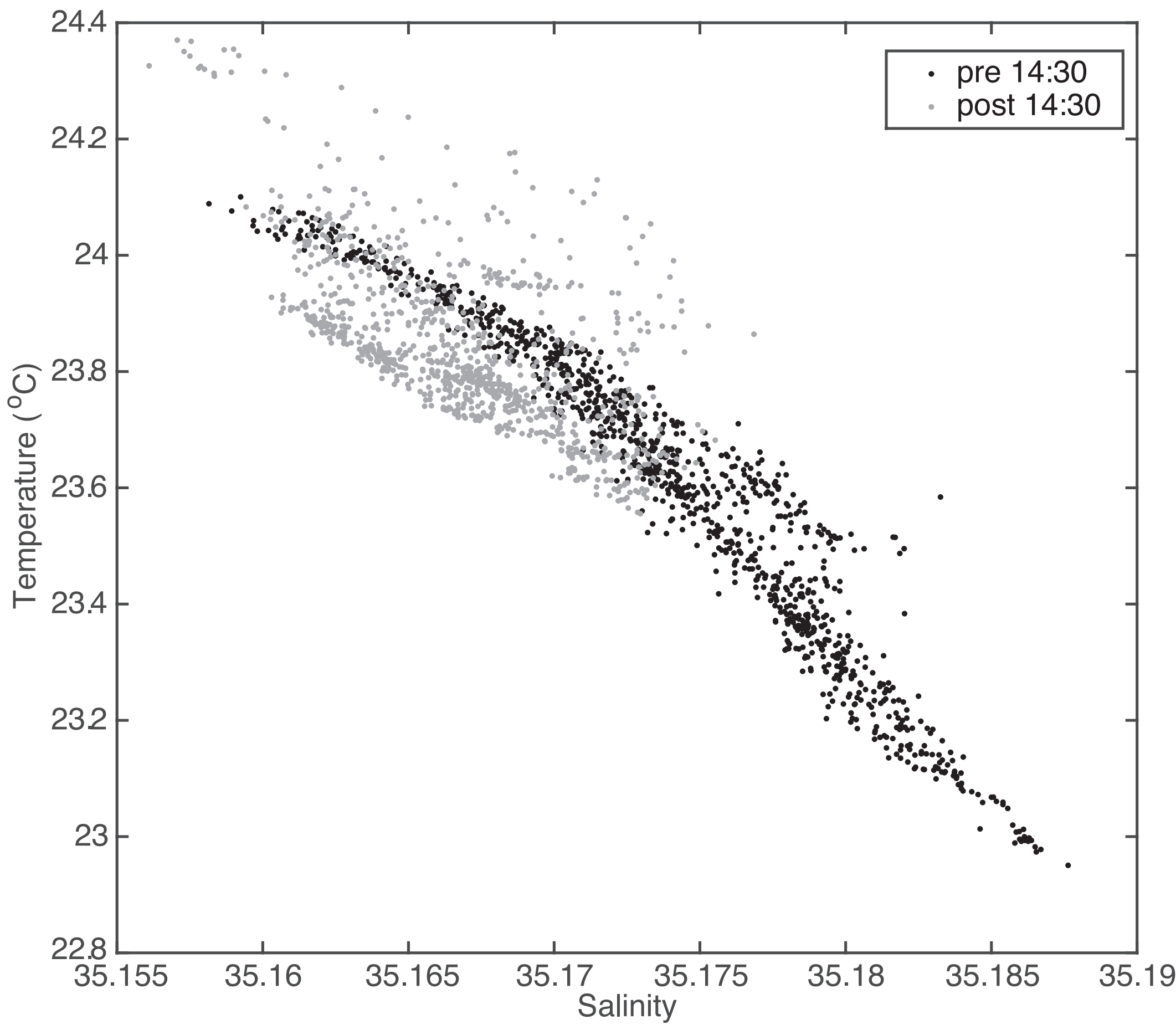


Semidiurnal tidal-band temperature standard deviations and velocity ellipses
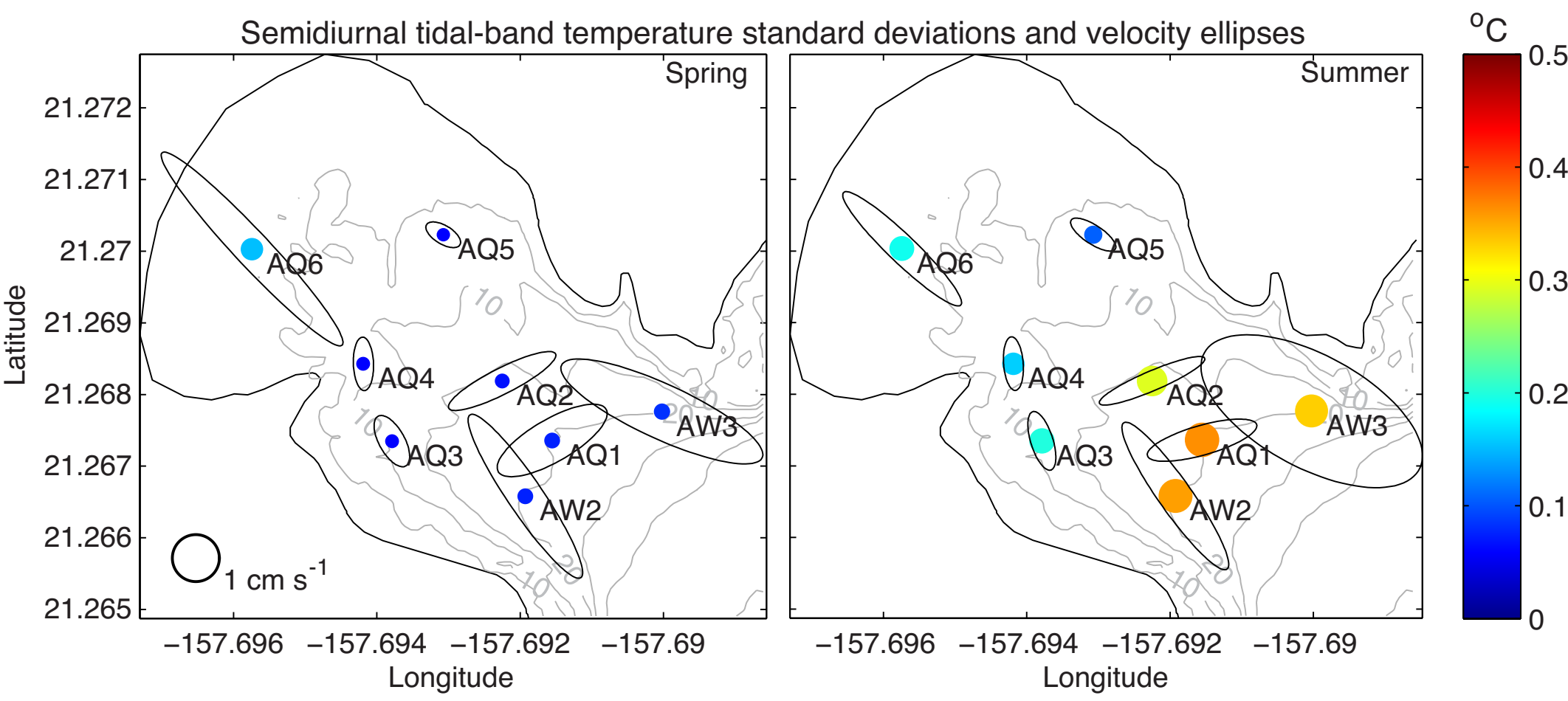
Longitude 